\title{
A AUTOPOIESE DO DIREITO E A TRANSPARÊNCIA DAS FONTES DE FINANCIAMENTO DO BNDES
}

\author{
THE AUTOPOIESE OF LAW AND THE TRANSPARENCY \\ OF THE SOURCES OF FINANCING OF THE BNDES
}

GABRIELA EULALIO DE LIMA ${ }^{1}$

\section{RESUMO}

O artigo objetivou evidenciar a importância da transparência na atuação do Banco Nacional de Desenvolvimento Econômico e Social (BNDES), peculiarmente, no critério das suas fontes de financiamento, ponderando que este instituto, tende a criar um ambiente jurídico favorável a consolidação da confiabilidade para com a sociedade brasileira. Isto em razão da transparência conformar uma espécie de regulação para o sistema financeiro público. Como referencial teórico, o trabalho se valeu da teoria dos sistemas de Niklas Luhmann, com ênfase na autopoiese do direito e no alcance do código binário "lícito/ilícito", propondo que a não execução dos preceitos normativos do instrumento da transparência pelo Banco, derivaria numa crise sobre o subsistema do direito da ilicitude, com implicações negativas para os cidadãos nacionais e empobrecimento do sistema jurídico com a ineficácia da norma. Como resultados prévios, o artigo destacou que a transparência traduz ao BNDES maior credibilidade no mercado financeiro nacional e internacional, capaz de reverter a imagem negativa marcada pela corrupção. Para tanto, o debate se construiu a partir da pesquisa documental e bibliográfica, com base no método dedutivo, procedendo com a apreciação da transparência dentro de uma relação lógica com a sua aplicação às fontes de financiamento do BNDES, compreendendo os aspectos constitucionais e infraconstitucionais da sua regulação.

PALAVRAS-CHAVE: Autopoiese. Banco Nacional de Desenvolvimento Econômico e Social. Código binário. Teoria dos Sistemas. Transparência.

\section{ABSTRACT}

The article was aimed at highlighting the importance of transparency in the operations of the National Bank of Economic and Social Development, uniquely on the criterion of their sources of funding, noting that the institute is creating a legal environment favorable to the consolidation of the trust with the people of brazil.

1 Doutoranda e Mestre em Direito, com a área de concentração Empreendimentos Econômicos, Processualidade e Relações Jurídicas pela Universidade de Marília - UNIMAR (2016). Especialista em Direito Material e Processual do Trabalho pelo Centro Universitário de Rio Preto - UNIRP (2015). Graduada em Direito pela Universidade do Estado de Minas Gerais - UEMG, campus de Frutal (2010). Autora do livro "O Consumo Colaborativo no Contexto da Sociedade Líquida: uma análise sociológica, econômica e jurídica" (2017). Coordenadora e Docente Superior de curso de graduação em Direito. Associada do Conselho Nacional de Pesquisa e Pós-Graduação em Direito - CONPEDI desde 2014. Editora de Seção na Revista Científica da Faculdade de Educação e Meio Ambiente - FAEMA, área de conhecimento Direito. Advogada. Bolsista na qualidade de pesquisadora, pela Fundação de Amparo à Pesquisa do Estado de Minas Gerais - FAPEMIG, com o trabalho de iniciação científica "Dignidade da Pessoa Humana sob a Incumbência do Estado" (2009/2010). http://orcid.org/0000-0003-2319-8390. gabrielaeulalio.adv@hotmail.com . 
This is on the grounds of transparency, to conform to a kind of regulation for the financial system to the public. As a theoretical framework, the work made use of the systems theory of Niklas Luhmann, with focus on the autopoiese of law and the reach of the binary code of lawful/unlawful, suggesting that the non-implementation of the provisions of the normative instrument of transparency for the Bank, derived on the crisis in the sub-system of the law of illegality, with negative implications for the country's citizens and the decline of the legal system and the inefficiency of the law. As the previous results, the article pointed out that transparency translates to the BNDES, the greater the credibility on the financial market, the national and international level, is able to reverse the negative image that is marked by corruption. To this end, the discussion was built from a survey and interviews, based on the deductive method, which is the assessment of transparency within a logical relationship with the application of the sources of financing of the BNDES, consisting of the aspects of constitutional and infra-constitutional from your system.

KEY-WORDS: Autopoiese. National Bank of Economic and Social Development. Binary Code; Systems Theory. Transparency.

\section{INTRODUÇÃO}

A pesquisa que será apresentada no presente artigo, refletirá a eficácia do instrumento da transparência para as fontes de financiamento do Banco Nacional de Desenvolvimento Econômico e Social (BNDES), fazendo uma análise sócio jurídica acerca dos elementos teóricos e normativos para a sua regulação.

Para tanto, o debate se justifica, na necessidade de transpor a transparência como um importante instrumento disponível no sistema jurídico nacional, capaz de enobrecer o relacionamento do Banco com a sociedade brasileira, então marcada pela desconfiança, dado o caos político, econômico e social instalados na atual conjuntura do país.

Nessa linha, a propósito do instrumento da transparência, não é imprudente afirmar que este pode ser conectado com vários outros embates sociais e jurídicos, mas no cerne das atividades desempenhadas pelo BNDES, possui uma característica básica na sua atuação, a natureza pública. Esta assertiva, revela a imprescindibilidade do cumprimento dos preceitos constitucionais e infraconstitucionais, pois que, a sua não observância ou mera escusa de cumprimento, resultará numa gama de problemas perenes, marcados pela insegurança jurídica, que impõe aos cidadãos ambiguidades sobre as operações que são realizadas com os recursos captados pelo Banco Nacional de Desenvolvimento Econômico e Social, e que, em tese, devem ser devolvidos às suas fontes originárias.

Referenciada a problemática, o objetivo do artigo se dedicará a análise desta à luz da teoria dos sistemas de Niklas Luhmann, materializando a autopoiese do direito como um dos subsistemas indispensáveis para a sociedade, seguindo a lógica estabelecida no núcleo da teoria, que possui por código binário, o lícito/ilícito. 0 escopo, portanto, será relevar que a materialização da transparência pelo BNDES nas suas atividades de financiamento - captação e devolução -, sobressai do papel que o Estado possui sobre a ordem econômica nacional, sendo-Ihe própria a responsabilidade de interferir, legitimamente, nas condutas dos agentes econômicos, com o destaque para os financiamentos públicos.

A fim de contextualizar esses elementos, a pesquisa iniciará abarcando a importância do Banco para o Brasil, que partindo de uma apreciação normativa, poderá desde a sua cria- 
ção até as metamorfoses ocorridas com o tempo, considerando a integração de preocupações sociais as políticas ao desenvolvimento das suas atividades; na sequência, ingressará na discussão das fontes de financiamento, buscando aclarar o rol das fontes de recursos que subsidia à concretização das atividades do Banco, bem como os valores específicos sobre as captações e as devoluções ao longo do tempo; por fim, a pesquisa tratará de forma dedicada da pujança legal da transparência do BNDES, buscando sedimentar cientificamente as dicotomias e/ou os conflitos entre os princípios envoltos no tema.

Para tanto, o método a ser utilizado no trabalho será o dedutivo, que procedendo da análise geral da discussão, abalizando o tema transparência dentro de uma relação lógica com a sua aplicação as fontes de financiamento do BNDES, buscará compreender os aspectos constitucionais da regulação. A consolidação do artigo se dará pela pesquisa exploratória, observando que apesar do aglomerado normativo que envolve o instrumento da transparência, a sua eficácia sobre as fontes de financiamento do BNDES, sob a perspectiva da teoria dos sistemas de Niklas Luhmann, indica que a não execução dos preceitos relativos as normas vigorantes do instrumento, tende a suscitar uma crise sobre o código binário lítico/ ilícito do subsistema do direito, refletindo resultados negativos à sociedade brasileira, por se empobrecer com a ineficácia do sistema jurídico em debate.

\section{O PONTO DE PARTIDA DO BNDES}

Criado pela Lei Federal n. ${ }^{0}$ 1.628, de 20 de junho de 1952, o Banco Nacional de Desenvolvimento Econômico (BNDE), foi jurisdicionado ao Ministério da Fazenda com o objetivo fundamental de operar como um órgão formulador e executor de políticas nacionais direcionada ao desenvolvimento econômico (BRASIL, 1952), que num primeiro estágio dedicou-se aos investimentos de infraestrutura, mas que com a criação de estatais, aos poucos passou a investir também na iniciativa privada e na indústria e, posteriormente, no setor agropecuário, e nas pequenas e nas médias empresas, chegando às décadas de 80 e 90 com outras linhas de investimentos, foco ábdito do presente trabalho. (BNDES, [ca. 2010])

Em 1971, através da Lei Federal n. ${ }^{0}$ 5.662, de 21 de junho, o Banco Nacional de Desenvolvimento Econômico, originalmente criado como uma autarquia federal, passou por uma importante transformação, sendo enquadrado na categoria de empresa pública, dotado de personalidade jurídica de direito privado, com patrimônio próprio, vinculado ao Ministério do Planejamento e Coordenação Geral, o que Ihe admitiu uma maior flexibilidade na contratação de pessoal, liberdade nas operações de captação e de aplicação dos recursos, e menor interferência política. (BRASIL, 1971).

Já no tocante ao foco, intrinsecamente, econômico, com o Decreto-Lei Federal n. ${ }^{\circ}$ 1.940, de 25 de maio de 1982, revelou um grande marco para as nuances da atuação do Banco, com a integração de preocupações que iam do social ao político do seu desenvolvimento, destaques que inclusive refletiram no nome jurídico, passando de Banco Nacional do Desenvolvimento Econômico (BNDE) para denominar-se Banco Nacional de Desenvolvimento Econômico e Social (BNDES), como é conhecido e reverenciado atualmente. (BRASIL, 1982) 
Todas estas transformações, distinguem o BNDES como uma instituição singular, ou seja, o descaracteriza de ser uma instituição anômola. Este diagnóstico é auferido da atuação das instituições privadas que por seu modus operandi, não conseguem operar perante riscos e o horizonte de longo prazo necessário para algumas atividades decisivas o desenvolvimento. Igualmente, não abonam recursos eficientes e satisfatórios para a intermediação financeira de atividades veementes em externalidades. (PEREIRA; MITEFHOF, 2018, n.p.)

Somada às distintas mutações produzidas pela norma que do Banco, a Era da Globalização, tonificada no século XXI, apresentou ao BNDES um desafio ainda mais pontual, de materializar o aclive social na missão do Banco, justificando a preocupação na necessidade de se promover a competitividade da economia brasileira em consonância aos aspectos da sustentabilidade, da geração de emprego e de renda, e da redução das desigualdades sociais e regionais; apoiando, para tanto, projetos que apresentassem como um ponto peculiar, o desenvolvimento local e regional, atrelado ao compromisso socioambiental e a capacidade de inovação, questões cada vez mais urgentes, no contexto do dinamismo e das constantes transformações advindas na contemporaneidade. (BNDES, [ca. 2010])

O fato é que é, historicamente, isto é, durante a maior parte da existência do BNDES, existe uma crítica que o aponta como o banco que opera em prol, ou pelo menos, com maior inclinação, para o desenvolvimento da indústria nacional, isto por considerar que foi e ainda é, o setor mais beneficiado com a concessão de crédito pela instituição. (BARBOZA; FURTADO; GABRIELLI, 2019, n.p.)

Deste modo, pode-se afirmar que o BNDES se consagra no século XXI, como uma empresa pública federal, que partindo das fontes de financiamento - como será adiante destacado com os pormenores -, atua como agente econômico público, destinado a apoiar a realização de investimentos nos mais variados segmentos da economia brasileira, com destaque para a concessão de financiamentos a longo prazo no País, objetivando a promoção do aumento da competitividade e do fortalecimento do desenvolvimento nacional dentro dos quadrantes econômicos e sociais -, apoiando o avanço social e o cultural, a fim de cooperar para a eficácia dos propósitos constitucionais, com a ampliação do acesso aos brasileiros e aos estrangeiros residentes no País, condições para uma vida melhor, com mais educação, saúde, emprego e cidadania.

E possuindo como característica básica na sua atuação, a natureza pública, é intrínseco ao BNDES a existência de alguns deveres que os bancos privados não têm e essas obrigações de forma muito simples, mas ao mesmo tempo, muito impactantes são direcionadas pelas diretrizes jurídicas em vigor no Brasil: a começar pela Constituição da República de 1988, que no seu o artigo 37, definiu com clareza quais são os princípios da administração pública - e todos eles se aplicam ao BNDES enquanto banco público - . Destarte, essa é a forma de operacionalização que o Banco deve destacar nas suas atividades internas e esperar que o externo tenha sobre o exercício das suas atividades, o que vem a colaborar para a discussão da regulação a partir da transparência, como se discutirá de forma dedicada no terceiro capítulo.

Pois bem, a compreensão de que ao BNDES aplicam-se os princípios da administração pública e observados estes à luz das atividades essenciais do BNDES, pelo menos aparentemente, cogita-se haver um conflito, isso levando em consideração o direito à intimidade do tomador de recursos do Banco - também garantida pela Lei Complementar Federal n. ${ }^{\circ}$ 
105, de 10 de janeiro de 2001 - (BRASIL, 2001); e sendo o Banco Nacional de Desenvolvimento Econômico e Social uma instituição financeira pública, adstrito ao cumprimento dos princípios da administração pública, tem-se a proeminência do princípio da publicidade, que restou melhor direcionado quando do advento da Lei Federal n. ${ }^{\circ} 12.527 / 2011$, viabilizando a sociedade e a imprensa, a possibilidade real de ter acesso às informações dos órgãos públicos e das entidades controladas direta ou indiretamente pela União, estados, Distrito Federal e municípios.

Diante dessa dicotomia, o BNDES se empenhou em operar para encontrar um equilíbrio entre os princípios da administração pública e a sua atuação bancária, tendo chegado ao resultado que é necessário ter uma percepção clara acerca do que efetivamente constitui sigilo bancário, considerando-o o contexto de informações e de documentos entregues pelos tomadores de recursos, com a finalidade de convencer o BNDES a liberar os recursos, como v.g., planos de negócios, segredos industriais, estratégias de enfrentamento à concorrência de mercado, enfim, todo o conjunto de informações que correspondam aos segredos comerciais e industriais que o Banco recebe dos seus tomadores. Portanto, são essas as informações que devem ser mantidas em confidencialidade, em obediência aos preceitos transcritos no texto da Lei Complementar Federal n. ${ }^{\circ}$ 105/2011, que, tangentemente, veda a publicidade.

Num segundo plano, recebidas referidas informações, o Banco faz uma análise sobre a capacidade de pagamento dos tomadores sobre um crédito pretendido e esta análise, tal como ocorre nas demais instituições financeiras destinadas a financiamentos - com a única diferença do BNDES não cuidar de uma empresa privada, que vende seus serviços com o objetivo singular na obtenção de lucros -, é desempenhado como uma forma instrumental para repor os ativos utilizados pelo Banco, para que esse prossiga colaborando com o desenvolvimento de outros tomadores de recursos e essas informações também não devem ser divulgadas, pois representa apenas uma apreciação subjetiva que o BNDES faz sobre a capacidade de pagamento dos tomadores. (BNDES, 2018).

E por fim, a vedação da publicidade também circunda o cerne do sigilo bancário, que seguindo a legislação apropriada sobre o assunto - citada Lei Complementar Federal n. ${ }^{\circ}$ 105/2011 -, figura exatamente a percepção sobre o status de adimplência e de inadimplência dos tomadores dos recursos, e qual viria a ser o saldo devedor dos seus tomadores com a instituição, que são possíveis através das fontes de financiamento do BNDES como se verá a seguir.

\section{FONTES DE FINANCIANAMENTO DO BNDES E O PAPEL SOCIAL}

Antes de ingressar na discussão propriamente dita, necessário frisar que em território brasileiro, o BNDES é consagrado como o ofertante responsável de capital a longo prazo às empresas, de modo a colaborar para o movimento da economia do país (TARANTIN JUNIOR; VALLE, 2015, p. 333). O papel das fontes de financiamento, para tanto, neste processo de 
composição estrutural do capital, possui significativa expressividade para o mercado de capitais.

Neste contexto, para a concretização dos financiamentos de projetos de investimentos, o Banco Nacional de Desenvolvimento Econômico e Social necessita de fontes de recursos, a fim de subsidiar à concretização das suas atividades e é sobre esse destaque que se abrirá a discussão a seguir.

Primeiramente, destaca-se o Tesouro Nacional, que desde a sua criação em 1952, foi indicado como uma importante fonte de financiamento do Banco (BRASIL, 1952, artigo 11, inciso I), que conjuntamente a outras fontes governamentais, como o Fundo de Amparo ao Trabalhador (FAT), os Programa de Integração Social (PIS) e o Programa de Formação do Patrimônio do Servidor Público (PASEP), concebem parcela significativa da estrutura de capital do BNDES, correspondente a $71,9 \%$ (setenta e um vírgula nove por cento) do total dos seus recursos em 31 de março de 2019 - estimando-se somar o percentual de $74,7 \%$ (setenta e quatro vírgula sete por cento) até 31 de dezembro de 2019. (BNDES, 2019)

Outros fundos governamentais, como v.g., Fundo da Marinha Mercante (FMM), Fundo de Garantia do Tempo de Serviço (FGTS) e Fundo de Investimento (FI-FGTS); captações no exterior, por meio de organismos multilaterais ou emissão de títulos (bonds²); emissão pública de debêntures; e emissões privadas de Letras de Crédito do Agronegócio (LCA) e de Letras Financeiras, completam a estrutura das fontes de recurso do Banco Nacional de Desenvolvimento Econômico e Social. (BNDES, 2019).

\subsection{DO TESOURO NACIONAL}

Idealizado no ano de 2002, o Tesouro Direto surgiu no contexto econômico nacional com o intuito de democratizar o acesso popular aos títulos públicos, permitindo aplicações em valores a partir de $\mathrm{R} \$ 30,00$ (trinta reais). Cuida, portanto, de um programa brasileiro desenvolvido em parceria com a Bolsa de Mercadorias \& Futuros (BM\&F) Bovespa, para a venda de títulos públicos federais a pessoas físicas, por meio da internet. (BRASIL, s.d.)

Segundo informações destacadas no sitio do Banco, em 2015 essa fonte ocupou 56,3\% (cinquenta e seis vírgula três por cento) do total das fontes de recurso do BNDES, já em 2019 representou um percentual menor, $36,6 \%$ (trinta e seis vírgula seis por cento). (BRASIL, 2019)

Pois bem, em valores, os percentuais dos recursos financeiros do Tesouro Direto integram, respectivamente, os números a seguir: a) Captações: ano 2014 (R\$ 60 bilhões), ano 2013 (R\$41 bilhões), ano 2012 (R\$55 bilhões), ano 2011 (R\$50,2 bilhões), ano 2010 (R\$ 82,4bilhões), ano 2009 (R\$105 bilhões) e ano 2008 (R\$22,5 bilhões), somando a monta de R\$416,1 bilhões - com o destaque para a captação de $R \$ 24,7$ bilhões destinado ao BNDES para permitir a participação na BNDESPAR ${ }^{3}$ no aporte à capitalização da PETROBRÁS -; e b) Devoluções: ano 2019 (R\$30 bilhões), ano 2018 (R\$130 bilhões), ano 2017 (R\$50 bilhões),

2 Espécie de garantia de uma promessa, representam títulos de dívida.

3 Corresponde ao BNDES Participações S/A., que é uma sociedade por ações com registro de companhia aberta perante a Comissão de Valores Mobiliários, gestora de participações sociais e uma das três subsidiárias integrais, do Banco Nacional de Desenvolvimento Econômico e Social. 
ano 2016 (R\$113,221 bilhões) e ano 2015 (R\$15,766 bilhões), totalizando R\$338,987 bilhões. (BNDES, 2019)

Tais dados apontam uma diferença de $\mathrm{R} \$ 77,12$ bilhões, a ser devolvido pelo Banco Nacional de Desenvolvimento Econômico e Social ao Tesouro Direto.

Segundo Ernani Teixeira Torres Filho e Fernando Nogueira da Costa: "O Tesouro Nacional oferece aos investidores risco soberano, para captar em longo prazo, tanto no mercado financeiro doméstico, quanto no internacional." (TORRES FILHO; COSTA, 2012, n.p.). Isto torna esta fonte de financiamento apta a viabilizar a realocação dos recursos em prazos mais adequados, a fim de direcionar os setores prioritários em prol do desenvolvimento nacional.

\subsection{DO FUNDO DE AMPARO AO TRABALHADOR}

\section{(FAT) E DO FUNDO PIS-PASEP}

Sobre o Fundo PIS-PASEP, importante destacar que com a promulgação da Constituição da República de 1988 , o seu artigo $239, \S 1^{\circ}$, apresentou que pelo menos $40 \%$ (quarenta por cento) da arrecadação do PIS-PASEP, deveria destinar-se ao financiamento de programas de desenvolvimento econômico através do BNDES, abarcando que não apenas o trabalhador desempregado, mas também as condições de novas oportunidades de emprego também estariam protegidas constitucionalmente. (BRASIL, 1988, artigo 239, §1º)

Em 1990, contudo, com o advento da Lei Federal n. ${ }^{\circ}$ 7.998, de 11 de janeiro, o Fundo PIS-PASEP foi extinto - não sendo realizadas captações desde então - e foi criado o Fundo de Amparo ao Trabalhador (FAT), passando a arrecadação daquele a ser destinada ao FAT, configurando assim, a sua principal fonte de recurso. (BRASIL, 1990)

Entretanto, tais mudanças não modificaram a essência constitucional, pois que, os recursos continuam sendo repassados ao BNDES, garantindo uma fonte estável para a execução de investimentos no desenvolvimento econômico e social do Brasil.

Não obstante, o aporte do FAT Constitucional é consagrado como de importância máxima para o Banco, que na concepção de Ernani Teixeira Torres Filho e Fernando Nogueira da Costa se deve aos fatos de: "[...] ser fonte estável e garantida de recursos, que historicamente vinha mantendo-se em níveis superiores aos respectivos pagamentos de rendimentos. Ademais, o FAT Constitucional era a principal fonte permanente do Banco [...]" (TORRES FILHO; COSTA, 2012, n.p.).

Esta fonte de recursos é empregada para acudir linhas de financiamento que visam apoiar negócios em diversificados setores e clientes de todos os portes - incluindo o microempreendedor e o agricultor familiar -, retornando ao FAT na forma de pagamento de juros. (BNDES, [ca. 2019])

Ainda sobre o Fundo de Amparo ao Trabalhador (FAT) e o Fundo PIS-PASEP, importa relevar que até o ano de 2009, esses dois fundos governamentais representaram parcela significativa da estrutura de financiamento do Banco. (BNDES, [ca. 2019])

Sob a lógica normativa, os recursos captados do Fundo de Amparo ao Trabalhador, são identificados como "FAT Constitucional" e são remunerados de acordo com a previsão da Lei Federal n. ${ }^{\circ} 13.483$, de 21 de setembro de 2017, ou seja, quando aplicados pelas instituições 
financeiras oficiais federais em operações de financiamento contratadas, a partir de $1^{\circ}$ de janeiro de 2018, serão remunerados pro rata die, pela Taxa de Longo Prazo (TLP), apurada mensalmente, composta pela variação do Índice Nacional de Preços ao Consumidor Amplo (IPCA), apurado e divulgado pela Fundação Instituto Brasileiro de Geografia e Estatística (IBGE), e pela taxa de juros prefixada, estabelecida em cada operação; e quando não aplicados em operações de financiamentos, ou seja, quando estiverem disponíveis para aplicação, serão apurados no Sistema Especial de Liquidação e de Custódia (Selic) média descontada do percentual de 0,09\% a.a. (nove centésimos por cento ao ano). (BRASIL, 2017, artigo $2^{\circ}$, caput e $\left.\S 3^{\circ}\right)$

Dada a inexistência de previsão normativa que preveja a devolução do principal desses recursos - salvaguardando os casos de insuficiência de caixa do Fundo para custear os programas de seguro-desemprego e de abono salarial -, subsiste apenas a cautela sobre o pagamento semestral de juros sobre esses recursos, de forma que o saldo do FAT Constitucional, é considerado uma fonte permanente e segura, com custos compatíveis com o financiamento de longo prazo de investimentos em atividades produtivas dívida subordinada, sendo parte dele computada no cálculo do Patrimônio de Referência do Banco. (BNDES, 2019)

Por meio da Resolução do Conselho Monetário Nacional n. ${ }^{\circ} 4.679$, de 31 de julho de 2018, o montante relativo ao FAT reconhecido no Nível II do Patrimônio de Referência (PR), limitou os percentuais aplicados ao valor desse recurso computado no mencionado nível em 30 de junho de 2018, estabelecendo um cronograma de redução de 10\% (dez por cento) ao ano a partir de $1^{\circ}$ de janeiro de 2020 até sua completa exclusão no ano de 2029. (BRASIL, 2018, artigo $1^{\circ}$ )

Além das transferências constitucionais, o Fundo de Amparo ao Trabalhador também passa pela captação de recursos pelo BNDES no formato "FAT Depósitos Especiais" - alocado pela Resolução n 439, de 2 de junho de 2005 -, que desponta que são remunerados atualmente pela Taxa de Longo Prazo (TLP), a partir da liberação dos empréstimos aos beneficiários finais e pelos mesmos critérios aplicados às disponibilidades de caixa do Tesouro Nacional, atualmente a taxa Selic, no caso de recursos ainda não liberados aos beneficiários finais. Além da remuneração, é devida amortização mensal. (BRASIL, 2005, artigo $4^{\circ}, \S 1^{\circ}$ )

Segundo informações divulgadas no sitio do BNDES, em 31 de março de 2019, o saldo de recursos do FAT somava $\mathrm{R} \$ 273,7$ bilhões, sendo $\mathrm{R} \$ 264,4$ bilhões inerente ao saldo do FAT Constitucional - sendo desse total, no primeiro trimestre de 2019 , captados $R \$ 4,7$ bilhões e $\mathrm{R} \$ 9,3$ bilhões do saldo do FAT Depósitos Especiais. E das captações do Fundo PIS/PASEP, cessadas desde a sua extinção em 1990, o saldo do Fundo auferido nesse mesmo período, somava a monta de $\mathrm{R} \$ 20,7$ bilhões. (BNDES, 2019)

\subsection{DEMAIS CAPTAÇÕES}

No tocante as captações externas, estas tendem a diversificar e a complementar as fontes de recursos do BNDES, consentindo na dissipação de riscos, na estimulação de outros emissores brasileiros e no estreitamento de relacionamentos com a comunidade financeira internacional, que desde o ano de 1953, o Banco vem captando recursos no mercado internacional por meio de operações de emissão de bonds e, desde 1972, procede com as captações 
através de empréstimos junto a organismos multilaterais, agências governamentais e outras instituições. (BNDES, [ca. 2010])

Os bonds, consagrados como os títulos externos emitidos pelo Banco, têm juros prefixados em processo de bookbuilding ${ }^{4}$ e amortização do valor principal em parcela única. Também segundo dados levantados pelo BNDES, no primeiro trimestre de 2019, apontam o saldo total com obrigações de emissões de bonds de R\$ 14,0 bilhões, que no exercício, foram liquidados $\mathrm{R} \$ 2,9$ bilhões referentes aos bonds emitidos em 2014. (BNDES, 2019)

Para as operações com instituições multilaterais e agências governamentais, o saldo registrado em 31 de março de 2019, somava $\mathrm{R}$ \$ 21,5 bilhões, resultado de operações concretizadas com instituições parceiras, a citar como exemplos: o Banco Interamericano de Desenvolvimento (BID), o Japan Bank for International Cooperation (JBIC), o Kreditanstalt für Wiederaufbau (KfW), o Nordic Investment Bank (NIB), a China Development Bank (CDB), a Agence Française de Développement (AFD), o Swedish Export Credit Corporation (SEK) e o Instituto de Crédito Oficial (ICO). Os recursos captados junto à essas instituições têm, geralmente, destinação específica a setores ou a segmentos empresariais e devem atender às condições da instituição credora, sendo as principais vantagens dessas fontes, o custo estável e o prazo de financiamento mais longo em relação às demais captações de mercado, além de seu caráter anticíclico ${ }^{5}$. Em momentos de escassez de recursos, marcados por crises internacionais ou por crises cambiais, os organismos mantiveram o nível de concessão de seus empréstimos. (BNDES, 2019)

\subsection{OUTRAS FONTES GOVERNAMENTAIS}

A história do Banco Nacional de Desenvolvimento Econômico e Social registra a captação de recursos através de fundos governamentais, objetivando concretizar fontes alternativas de recursos para apoio a projetos de investimento a longo prazo. Sendo contabilizado no primeiro trimestre de 2019, o saldo total de $\mathrm{R} \$ 32,6$ bilhões divididos entre o Fundo de Marinha Mercante (FMM) - R\$23,1 bilhões -, o FI-FGTS (Fundo de investimento do Fundo de Garantia do Tempo de Serviço) - R\$2,5 bilhões - e o FGTS (Fundo de Garantia do Tempo de Serviço) - R\$2,8 bilhões. (BNDES, 2019)

O Fundo da Marinha Mercante é administrado pelo Ministério da Infraestrutura e é destacado como o fundo de natureza contábil, proposto a aprovisionar recursos para o desenvolvimento da Marinha Mercante e da indústria de construção, e de reparação naval brasileiras. (BRASIL, s.d.)

Já o Fundo de Investimento do Fundo de Garantia do Tempo de Serviço, foi instituído nacionalmente pela Lei Federal n. ${ }^{\circ} 11.491$, de 20 de junho de 2007, ficando caracterizado pela aplicação de recursos do FGTS, destinado à investimentos em empreendimentos dos setores aeroportuários, energéticos, rodoviários, ferroviários, hidroviários, portuários e saneamento, de acordo com as diretrizes, critérios e condições que dispuser o Conselho Curador do FGTS. (BRASIL, 2007)

4 É um processo que visa encontrar um preço justo para uma oferta pública de valores mobiliários, através da análise da demanda pelos papeis feita por um coordenador junto com investidores institucionais.

5 Consiste no conjunto de ações governamentais voltadas a impedir, sobrepujar, ou minimizar, os efeitos do ciclo econômico. 
Por derradeiro, o Fundo de Garantia do Tempo de Serviço, foi instituído pela revogada Lei Federal n. ${ }^{\circ}$ 5.107, de 13 de setembro de 1966 e, atualmente, é regido pela Lei Federal n. ${ }^{\circ}$ 8.036, de 11 de maio de 1990, tendo por objetivo máximo, proteger o trabalhador que tenha o seu contrato celetista rescindido sem justa causa, sendo no ato da efetivação da contratação, aberta uma conta vinculada ao contrato de trabalho, em que a cada início de mês, os empregadores depositam em nome dos seus empregados, o valor correspondente a $8 \%$ (oito por cento) do salário de cada um deles. Portanto, é a constituição de saldos das contas vinculadas a lei vigente e a outros recursos incorporados, devendo ser aplicados com atualização monetária e juros, de modo a assegurar a cobertura de suas obrigações. (BRASIL, 1990)

\subsection{OUTRAS OBRIGAÇÓES}

Dentro do grupo das "outras obrigações", as captações mais importantes vêm do mercado interno, destacando-se as debêntures emitidas pela BNDESPAR, as Letras de Crédito do Agronegócio (LCA) e as Letras Financeiras, que em 31 de março de 2019, representavam um saldo no passivo de $R \$ 4,8$ bilhões, sendo $R \$ 2,0$ bilhões correspondente a emissão de debêntures pela BNDESPAR; R\$0,4 bilhão traduziam o saldo de Letras de Crédito do Agronegócio (LCA), que para o BNDES servem para impulsionar a realização de leilões junto a instituições habilitadas em plataformas eletrônicas de negociação e a partir de agosto de 2017, passou a atuar como dealer do Banco Central (BACEN), ao realizar a intermediação das operações, captando recursos de instituições financeiras e repassando ao BACEN; e R\$2,4 bilhões pelas Letras Financeiras, resultado de duas emissões - em maio e em dezembro de 2018 -, com prazo de vencimento de 02 (dois) anos, cujo objetivo era compor estratégias desenvolvimentistas de novos instrumentos de captação de mercado, diversificando a base de investidores, com vias a preparar o Banco para atuar como emissor mais frequente no mercado local. (BNDES, 2019)

\subsection{FUNDO AMAZÔNIA (FA) E PATRIMÔNIO LÍQUIDO}

Arrematando o rol das fontes de recursos do BNDES, conforme informações disponíveis no próprio sitio do Banco, para financiamentos a longo prazo, também destaca-se o Fundo Amazônia (FA) e o Patrimônio Líquido, sendo aquele destinado para financiamentos de projetos de prevenção, de monitoramento e de combate ao desmatamento e de promoção da conservação e do uso sustentável das florestas no Bioma Amazônia, fechado o primeiro trimestre com o total de $\mathrm{R} \$ 3,6$ bilhões, líquido da parcela de 3\% (três por cento) destinada à cobertura de custos; e o Patrimônio Líquido com o total de R\$95,1 bilhões, refletindo o impacto positivo do ajuste de avaliação patrimonial, líquido de tributos ( $R \$ 4,5$ bilhões) e do lucro líquido do período (R\$̣11,1 bilhões). (BNDES, 2019)

Com estas fontes de recursos do BNDES, é perceptível que as instituições financeiras privadas deixam de ser congregar as únicas fontes de financiamento para o ambiente empresarial. O rol taxativo do Banco propõe alternativas de recursos disponíveis a grandes, médios, pequenos e micro empresários, proporcionando linhas de crédito para o desenvolvimento da atividade corporativa, bem como subsidiando o capital de giro. 
Barbara Coscrato Gonçalves, Camila da Silva Macedo e Juliana Leonardo de Oliveira Bergamini propõem que o BNDES: "[...] surge como uma importante opção de financiamento para as necessidades tanto de curto quanto de longo prazo, especialmente pelas taxas de juros reduzidas, as quais costumam ser mais interessantes do que as fornecidas pelas instituições financeiras tradicionais." (GONÇALVES; MACEDO; BERGAMINI, 2018, p. 109).

Destarte, consagrando-se as atividades empresariais importante fração para a economia brasileira, quanto mais amplo e organizado for o acesso ao capital por meio das fontes de financiamento do BNDES, maiores serão as perspectivas que o prosseguimento e a contribuição das corporações para o desenvolvimento nacional.

\section{TRANSPARÊNCIA E BNDES}

Depois dos realces dedicado para as fontes de financiamento do Banco Nacional de Desenvolvimento Econômico e Social, é possível afirmar o quão importante é ter nota pública sobre os valores captados e aos devolvidos às fontes de recursos, consolidando, certa feita, uma prestação de contas ou um "agir honesto" para com a sociedade, tão desacreditada do contexto político, econômico e social, na atual conjuntura brasileira.

Eis que essa integridade do BNDES, nada mais é do que o amadurecimento da norma constitucional e infraconstitucional, que revelou a transparência como o instrumento facilitador para o cidadão brasileiro de controle social das ações estatais, que na concepção de Maria Inês Souza Bravo e Maria Valéria Costa Correia: "No processo de redemocratização do país a expressão controle social passa a ser compreendida como o controle da sociedade sobre o Estado." (BRAVO; CORREIA, 2012, n.p.).

Outrossim, Lucas Gonçalves da Silva e Patrícia Verônica Nunes Carvalho Sobral de Souza são precisos em ponderar que: "A participação do indivíduo na vida política é um modelo eficiente do desenvolvimento popular. Os países mais desenvolvidos possuem um controle social latente, uma vez que os cidadãos preocupam-se com a aplicação das verbas públicas." (SILVA; SOUZA, 2017, p. 214)

Pois bem, no Brasil, a promulgação da Lei Federal n. ${ }^{0} 12.527$, de 18 de novembro de 2011 (popularmente conhecida por Lei de Acesso a Informação), em vigor desde 16 de maio de 2012, revitaliza esta participação do cidadão nacional, ratificando o direito constitucional de acesso às informações públicas - previsto no inciso XXXIII do artigo $5^{\circ}$, no inciso II do $\S$ $3^{\circ}$ do artigo 37 e no $\S 2^{\circ}$ do artigo 216 da Carta Maior (BRASIL, 1988) -, restou regulamentado. Sendo criado por intermédio desta norma especial, mecanismos que possibilitassem a todos, indistintamente, se pessoas físicas ou jurídicas, sem qualquer justificativa, o acesso as informações dos órgãos públicos e das entidades controladas direta ou indiretamente pela União, estados, Distrito Federal e municípios. (BRASIL, 2011)

O intuito fundamental do legislador com a citada norma, foi trazer um contexto mais eficaz de probidade para o Brasil, que por meio da transparência de informações de interesse geral ou coletivo, advindas dos órgãos públicos e das entidades controladas direta ou indiretamente pelos Entes da Federação, passaria a seguir o exemplo de países que, por meio do 
mecanismo da transparência, lograram êxito para se tornarem Estados-Nações desenvolvidos, dentro de uma perspectiva mais igualitária, com a aplicação mais correta dos recursos e mais distante da corrupção.

Janyluce Rezende Gama e Georgete Medleg Rodrigues consideram: "A transparência e o acesso às informações públicas são alguns dos pilares fundamentais de um governo aberto à participação social." (GAMA; RODRIGUES, 2016, p. 48). Isso faz destes temas, objetos cada vez mais explorados pela ciência e pela academia, justamente, por representar um marco da implementação eficaz dos preceitos fundamentais que já estavam disciplinados no Texto Constitucional de 1988.

A transparência, especificamente, aclara como é governado e/ou administrado os bens públicos, despontando como as receitas são obtidas, como são e porque são gastas (CAMPOS; PAIVA; GOMES, 2013, n.p.). Deste modo, o BNDES apesar de não possuir o conceito de estatal dependente e, via de consequência, não ser regido pela Lei Federal n. ${ }^{\circ} 4.320$, de 17 de março de 1964, Lei de Finanças Públicas (BRASIL, 1964), tem a sua gestão contábil e financeira norteada pelas regras da Lei Federal n. ${ }^{\circ}$ 6.404, de 15 de dezembro de 1976, Lei das Sociedades Anônimas (BRASIL, 1976), ocupando o quadrante das instituições bancárias públicas (BNDES, s.d.). Destarte, compõe o rol de instituições que deve operar sob o pálio da transparência, dando publicidade a todos os seus movimentos, sejam eles ativos e/ou passivos.

No atual contexto social e jurídico, a informação é consagrada como um dos fatores essenciais para a melhor performance das empresas, que ganhou espaço significativo no setor público, pois que, este mais do que qualquer outro, necessita dar respostas expressivas à sociedade. (CAVALCANTI; DAMASCENO; SOUZA NETO, 2013, n.p.)

Contudo, apesar da decretação da Lei de Acesso a Informação em 201 1, apenas em outubro de 2016, através de ação conjunta entre a Ordem dos Advogados do Brasil, a Associação Nacional dos Auditores de Controle Externo dos Tribunais de Contas do Brasil, a Associação da Auditoria de Controle Externo do Tribunal de Contas da União e a Associação Nacional do Ministério Público de Contas, com base na lei, retro mencionada, oficiaram o Banco Nacional de Desenvolvimento Econômico e Social, solicitando que fosse disponibilizado no sitio do Banco, informações dos últimos 10 (dez) anos dos financiamentos externos, das operações internas e da parceria com instituições estrangeiras. O presente documento foi colocado em pauta de reunião e o diretor jurídico do BNDES da época, Marcelo de Siqueira Freitas, ponderou uma preocupação por parte da instituição em avançar rumo a transparência, deixando a prevalência de fazer operações ocultas sob o manto do sigilo bancário. (CONJUR, 2016)

Não obstante, outro importante órgão que teve peso no debate sobre a aderência do instituto da transparência ao Banco Nacional de Desenvolvimento Econômico e Social, foi Tribunal de Contas da União (TCU), que em 21 de agosto de 2018, realizou uma audiência pública conjunta com o Banco, cujo utilitário focal foi tratar sobre pontos mais avançados do tema, primando ampliar o acesso aos termos da legislação brasileira às atividades do BNDES; sendo alvitrado que sendo ele um banco de investimento, tal como qualquer outro no Brasil e no mundo - da mesma natureza -, toma recursos, seja dos acionistas, sejam os gerados internamente ou os do mercado; aplica sobre estes, uma taxa para remunerar os seus serviços e os disponibiliza a terceiros; tendo como pretensão elementar, gerar o retorno 
com as suas atividades, ou seja, a partir da aplicação desses recursos, materializando a intermediação financeira. (BNDES, 2018)

Ponderadas as vertentes do cumprimento estrito dos preceitos constitucionais e dos descritos nas leis especiais, o Banco Nacional de Desenvolvimento Econômico e Social ficou adstrito a observar melhor a Política de Transparência para o seu sistema, disponibilizando em seu portal a integralidade das informações livres da proteção legal do sigilo bancário, alocadas em seções específicas, que traduzem o rol de informações classificadas como de "Transparência Ativa", cuidando essas de informações apresentadas proativamente e de natureza diferente das que estão condicionadas a solicitação por parte da sociedade, categorizando a "Transparência Passiva". (BNDES, s.d.)

Tânia Carolina Nunes Machado Gonçalves e Marcelo D. Varella ponderam que: "[...] o direito fundamental de acesso à informação, pautado pela transparência ativa da Administração Pública, ou seja, a busca pela proatividade na divulgação das informações. Ambos são princípios constitucionais e, como tais, não há hierarquia entre eles." (GONÇALVES; VARELLA, 2018, n.p.)

Para tanto, o sítio do Banco apresenta opções que podem ser utilizadas pela sociedade civil e pelos órgãos de fiscalização, para obterem o acesso mais adequado às necessidades de cada qual, no tocante a transparência, sendo que para se obter informações de interesse geral e coletivo sobre o BNDES, imperioso que se registre um pedido de informação no e-SIC - http://www.acessoainformacao.gov.br/sistema/; para dúvidas operacionais, ou seja, para o recebimento de informações sobre os produtos financeiros do BNDES ou sobre pedidos de financiamento em aberto, contatar com a central "Fale Conosco" - pelo número 0800702 6337 -; e para fazer uma sugestão, denúncia ou reclamação, encaminhe uma mensagem para a Ouvidoria - através do número 0800702 6307. (BNDES, s.d.)

A propósito do instituto da transparência, que pode ser conectado com tantos outros embates sociais e jurídicos, acerca das atividades desempenhadas pelo BNDES, importante realçar que a sua materialização destaca, precipuamente, o papel do Estado na ordem econômica nacional, isso considerando que lhe é própria a incumbência de interferir legitimamente nas condutas dos agentes econômicos, através dos mais distintos mecanismos de fomento, que nessa pesquisa se destacam os financiamentos públicos, responsabilidade priorizada pelo constituinte de 1988. (BRASIL, 1988, caput do artigo 174)

A esse respeito, Celso Antonio Bandeira de Mello reverência que: "[...] com o advento da Constituição de 1988, tornou-se enfaticamente explícito que nem mesmo o planejamento econômico - feito pelo Poder Público para algum setor de atividade ou para o conjunto deles - pode impor-se como obrigatório para o setor privado." (MELLO, 1999, p. 178)

Dessa compreensão e do aglomerado normativo que circunda a aderência do tema transparência ao BNDES, traduz-se a leitura de que não é possível admitir qualquer escusa para a concretização da responsabilidade cogente estatal à realização dos princípios constitucionais, e isso, porque é a partir do cumprimento do prescritivo da norma legal, que há um avivamento dos princípios constitucionais da administração pública e, igualmente, da concretização da ordenação e/ou da regulação da atividade econômica desempenhada por meio dos financiamentos público, cujo objetivo é primordialmente a busca do bem público, que pode ser definido política e economicamente. (SALOMÃO FILHO, 2008, p. 21/23) 
E essa discussão sobre a transparência e as fontes de financiamento do BNDES, pode ser analisada à luz da teoria dos sistemas de Niklas Luhmann, materializando a autopoiese do direito como um dos subsistemas, que possui por código binário o lícito/ilícito. (LUHMANN, 2016, p. 65)

Considerando que dentro do Estado brasileiro a reprodução do sistema jurídico - em constante evolução -, concretiza-se por meio da Carta da República e das normas infraconstitucionais. Neste viés, o que foi realçado nesta pesquisa sobre as características intrínsecas do BNDES, enquanto banco público, é plausível considerar que o não cumprimento aos preceitos relativos à transparência, revelaria uma crise sobre o código binário lítico/ilícito do direito, que é refletido frontalmente na sociedade.

Niklas Luhmann revela que direito e sociedade estão acoplados estruturalmente, ou seja, relacionados por interdependência mútua, à medida que o direito compõe o esqueleto do sistema social, seu papel essencial destina-se a amortizar parte da complexidade desorganizada que a sociedade está submergida e, igualmente, tem por finalidade, fazer com que o seio social obtenha uma complexidade mais alta e estruturada. (LUHMANN, 2016, p. 69)

Sinteticamente, o direito se movimenta no sistema macro para atender as necessidades de ordenamento na sociedade, de forma que sem esse subsistema, não haveria orientação de condutas no meio social.

Não obstante, a respeito da evolução do subsistema do direito no contexto da teoria luhmanniana e a sua convergência com a transparência para as fontes de financiamento do BNDES, também é possível averiguar o seu sentido na linha de afinidade com outros subsistemas sociais - aplicáveis à essa discussão, o político e o econômico -, que por força das suas relações com um ambiente marcado pelo desenvolvimento de complexidades e de contingências sociais, remontam às estruturas da sociedade ao padecimento de pressões que apontam para o sentido de mudança. (LUHMANN, 1983, p. 172)

Esta afirmação se desponta de grande importância para transpor que a transparência um instrumento extraordinário para enobrecer o relacionamento do BNDES com a sociedade, vez que, para o tema fontes de financiamento, efetivamente, significa dar segurança jurídica e social aos brasileiros, sobre as operações que são realizadas com os recursos captados de fundos públicos e devolvidos às suas fontes originárias.

Ademais, a transparência na condução da política monetária também pode ser compreendida como uma ferramenta eficaz e justificada para firmar um contexto de assimetrias de informação entre a autoridade monetária pública e a sociedade civil, evidenciando que através do fomento ao desenvolvimento da cultura da transparência, há uma redução de incertezas e aumento da eficiência sobre a política monetária pública.

\section{CONSIDERAÇÓES FINAIS}

Em suma, os resultados obtidos neste trabalho apontam para as seguintes evidências empíricas: 
1) Ao realçar a importância da transparência nas fontes de financiamento do BNDES, cria-se um ambiente sócio jurídico mais propício a estabilidade, reforçado com o argumento de que a transparência espalha uma regulação do sistema financeiro público, que não pode e não deve ser neutra, seguindo os termos constitucionais, ajustados pela Lei Federal n. ${ }^{\circ}$ $12.527 / 2011$, que estabelece o dever de ser garantido o direito de acesso à informação, franqueada mediante procedimentos pragmáticos e ágeis, de forma transparente, clara e em linguagem de fácil compreensão;

2) Outrossim, a atuação em matéria de transparência no BNDES, concretiza a ação constitucional regulatória, que abrange que os financiamentos públicos estarão seguros, perpassado pelo processo de acompanhamento da implementação de um modelo e uma gestão de desenvolvimento da atividade econômica - sob a ótica da prestação de serviços públicos -, articulado por intermédio de um mecanismo legal infraconstitucional, que submerge a apreciação do impacto regulatório da gestão transparente das informações quanto a captação e a devolução das fontes de recursos utilizados pelo BNDES. Tudo isto, propicia um acesso mais amplo e claro com a divulgação dos seus resultados, o que via de consequência, resulta num movimento cíclico da atividade desenvolvimentista do Banco;

3) Nesse viés, a pujança da transparência sobre as fontes de financiamento do BNDES, analisado sob a perspectiva da teoria dos sistemas de Niklas Luhmann, alude que a não execução dos preceitos relativos as normas vigorantes ao instrumento da transparência pelo Banco, tende a suscitar uma crise sobre o código binário lítico/ilícito do subsistema do direito, refletindo resultados negativos à sociedade brasileira, por se empobrecer com a ineficácia do sistema jurídico sobre o debate;

4) Por derradeiro, destaca-se que a transparência traduz ao BNDES maior credibilidade no mercado financeiro nacional e internacional, apresentando-se no cenário econômico do Estado brasileiro, como uma instituição que opera em busca da harmonia entre as metas de desenvolvimento social e econômico do país, respeitando o tratamento das informações pessoais dos tomadores dos recursos, que deve ser feito de forma transparente e com respeito à intimidade, vida privada, honra e imagem desses, bem como às liberdades e garantias individuais, sem, contudo, deslembrar o papel fundamental da transparência no contexto social atual e no incremento econômico da produtividade dos setores da economia nacional, desvencilhando-se, o quão gradativo possível for, da imagem negativa da deterioração da credibilidade brasileira marcada pela corrupção.

\section{REFERÊNCIAS}

BARBOZA, Ricardo de Menezes; FURTADO, Mauricio; GABRIELLI, Humberto. A atuação histórica do BNDES: o que os dados têm a nos dizer? Brazilian Journal of Political Economy. vol. 39, n. 3, São Paulo, July/Sept., 2019. Disponível em: https://www.scielo.br/scielo.php?script=sci_arttext\&pid=S0101-31572019000300544\&tlng=pt. Acesso em 16 maio 2020.

BNDES. Acesso à informação: receitas e despesas. Disponível em: https://www.bndes.gov.br/wps/portal/site/home/acesso-a-informacao/acesso-informacao-receitas-e-despesas/!ut/p/z1/tZRfb9sgFMU_ jR8J1wFn9t6c1k3aO026Kn_MS4UdErMI4AJN1n76kSzaqmhzN3XIBXEF5_yOdC-Y4TImim_lijupFV_7c8F693 kyyob0BvLBZwghjUYX6fR8RNJxhGeHC_CHIQJm7e-nmGFWKde4GhelWgh7L5V10j1WB4IAarORAfBKWKsR- 
R1IttdnwiuufxV8IZEQIpOMWCeSIGmG53Rs0IVzgAng3jAkFtCBLimhchohDjyMSJYRHSSK6FRwDtRCz9ryzvd9LhZtLkkE6PMsjmo3CQUKOF100Cs_w4QXDp-sLz3Dbh0FGQzqkeLaVYocnah97je_-MeLwNYfbtzqcyk_755Dm I3f5YAlkzrr_Wf6Evve-8tEb5a9emwk_dF0zPhuvvCx39aG_8fzvmt2_IV8eHljqp0orJ745PH-fsflxVmtd_vgkUIWS2PMasRRGmM6j8eXaucZ-DCCA3W7XOVBOVnrbKY2vNDaARhu3Z7HSiRai3xnU2vpkp7q42Uw2MXICX5fjjNDiavvcv0bHjZVP5DkXs-_5pX6F/dz/d5/L2dBISEvZOFBIS9nQSEh/. Acesso em 15 maio 2020.

BNDES. Audiência pública BNDES e TCU sobre transparência - 21 de agosto de 2018. 2018. (1h18min44s). Disponível em: https://www.youtube.com/watch?time_continue=2283\&v=1dtr3h1Ah18. Acesso em 17 maio 2020.

BNDES. Fontes de recursos. Disponível em: https://www.bndes.gov.br/wps/portal/site/home/relacoes-com-investidores/fontes-de-recursos/fontes-recursos/!ut/p/z1/vVNNj5swEP0tOXB07AQTSG9sIG52A02jLU3gEhljgttgs7YD3f76mnajVasuVbVqfbHmQ2_ezLyBGdzDTJCWH4nhUpCTtdNsdvC3t4tViCfRJopDtL2bxJ8eNp673iK4uySgV16IYGbD0Xy9XOENipD78T0KV9EkwfENmq4x_AwzmFFhGIPBNBcFOwcutOHmTC8MHFTJmjllsROhRAIqa8BFy2xKIRXTDqJSGDai7ignhXRQ2Zv6ULCDYvSstNRXH7g6-pIN5QvMMaYleXMCSuxPAcaBB-bYpcDPvaJkQYkCMn1ucWAG2fAEdn29X6ewuXOXdgqLyMPL9eR27j4nDGCkloP_OocJ3LWcdTARUtV2bQ9_2eLqTxWS2Rs rDMPP_i184r8R_v6ynwEJ2DuZqngRHy0sMZWVaCnh_qXubBb_8viYhVbyfeibgfv_pXnbwvEk8583HYrcDSxXxUqmmBqflXVXxjT6nYMc1HXd-MJrfJTtOFfW01jIRirTs9PcsCtHo4jQDVFMUE5-B11 Jbbt8iQibOqkD9wl8LeOli9P79vvNB9B_EduBLH_qwtHoB43WKpo!/dz/d5/L2dBISEvZOFBIS9nQSEh/. Acesso em 17 maio 2020.

BNDES. Fundo de Amparo ao Trabalhador - FAT. Disponível em: https://www.bndes.gov.br/wps/portal/ site/home/transparencia/fundos-governamentais/fundo-de-amparo-ao-trabalhador-fat/fundo-amparo-trabalhador-fat/!ut/p/z1/tZXfk5owEMf_Fh98jAkSfvWNc6jegfWsZ1VenABBalVwler1v-9idWydE6915IFMNruf3Sz5BuzjOfZztk1XTKUiZ2uYL3xzaY27nZ5LtQHxHmwyftTG9LmvtyeU4NnegVx4XIL9P-NHg6FbxQ9fJiND748J_ oZ97le5KISCF0Ee8XKZ5qVK1SbcV9Akich4kyjJ8rJgkudhypok3uSRKGFk6jBBLINIgcAxYOuERUliWK3wRZhGeGFYgUYNZiPisDaijgkjp-048LL1yDZD4ljssJ2aev2PtKPGwa_v1 qyqF1wGTt_rOREZjB51j7i9zsCgXI_rOvrBoa7jfx06z18-E9cYP5CuR7VRX8MLKNK6vEkNz7Yp3-FpLmQGZ2By6iGIISGGw1BMLeghtQ3kUD1EVmBEMbdjYrM27pErGabmjRnq8eZ98VPrRvzTNU2A6Npy2BmuAMtUgtl8Fngei1zxEkkebmQpysor_f766rugn2rpTeF5jYAkX70QCRSKDIBbDi4gEQ4a2kc3QrORgGhATfs8y4gvj6mOtINu2MJqLYLfF4SbB7oNtUoec8llayPBnChVIJ-apEI2u1 1rX1drJbatQIKIAGQhpKqqK1PF3xX5e-hEILDLc-L5BztXXc2B_tCIUI_vk_vizfvijfvirRvxT9du3H-UwX_Ry6Isi6kyKaZrf9M0Y-v9u4ITIbZcujpRjUolzDW20F8nJ8GsLpuo_ELY--waQ!!/dz/d5/L2dBISEvZOFBIS9nQSEh/. Acesso em 17 maio 2020.

BNDES. Nossa história. Disponível em: https://www.bndes.gov.br/wps/portal/site/home/quem-somos/nossa-historia. Acesso em 17 maio 2020.

BNDES. Perguntas frequentes: De que forma o BNDES promove a transparência? Disponível em: https://www. bndes.gov.br/wps/portal/site/home/faq/institucional/3444444545/3426324/o-que-e/4564232. Acesso em 15 maio 2020.

BNDES. Recursos financeiros captados junto ao Tesouro Nacional. Disponível em: https://www.bndes. gov.br/wps/portal/site/home/transparencia/recursos-do-tesouro-nacional/recursos-financeiros-captados-junto-ao-tesouro-nacional/!ut/p/z1/vVXBctowEPOWDj4KybYEpjeHcSEBSmhCQ3xhZFkCpSA5soD27ytDaNIMgbQZ6ous9e7btyu_FUzhBKaKruWMWqkVXbj9fdqYNkeddjfGfh8IFxEaXfojfNOLg3ZC4N3WAb3xxAimL-OH_UFcxQ9ub4Yk7I0Q_AZTmDJICzuH95nKeTmVqrTSrtiWgYfmesk9ZA1VZUENV0xSD9FiIRIIVE9zXU4NZytTuhchFVWMS6NLD-2t4IUVMFpY6mLAw0pZDagGIpd6ZTRQdJexIIQwmTs6DYoQDRsgECQAOBQYUCxy0AojnGPRJK3If2rAkQrT9zTwiEN6vL93FV_n0m_1 ki4eov7wMkxQ3G33CU56fqcVPjk c06M_ETrXXz6jmIwuUCfB_rDnw3tHsvl2ka4La8k3cKy0Wbo03jz3EGOGEGIRIHDT9RBHBLRwyEAzI7ngkUARDWAXncgwbnwww3H4xnnhx80Pwl-dUpGTaWAG7cHMwVI7B1IJDSdCK_dzg700Ki_58PiYxk5x1acfFk 60SM7wRaUwwPTSAa65c8m14U5Z2-gaC2uZk5KHdnmmOf8txL3tObcrYbbQ2W6kxCoLI8fVcMENN_WVcea5tUX5yUMe2mw29S2v-kyv65IxIsJBFtrYil0pLT84Fg5Bz3XpqnyN-PrAXqlujN8-sHcNhRPw5KzwPjovfHBeeP-D8FenJu5fyuA_3jyHZfyvaMVyvlzCnxJ8_xptbsV8tpwOkpBUiyUZWaz7Yr9_Xpw1jmu1X2pk-Ok!/dz/d5/ L2dBISEvZOFBIS9nQSEh/. Acesso em 17 maio 2020.

BNDES. Ouvidoria. Disponível em: https://www.bndes.gov.br/wps/portal/site/home/quem-somos/canais-atendimento/ouvidoria/!ut/p/z1/tZNNU8MgEIZ_i4ccKVilTbyltlrb1M7o1BouHRJlixpIA03VXy-pOuNnHUflwrCzvM--7AlpvIJUsVoumJVasVt3TujBPA5H_QGZoBgRQIAUBwM8GXZ7BLfhbJuAvlgRgvT1_ZNztl8if3QcXfZGOBr78BJSSDNIS7uESaq4MHOpjJV2nWOr8NBSF8JDq7UogNGFNh7KmGLSAC4As0JxWQhltYfOupZcV5I1 kmUmOUz8FOOMt00Q5owAEjAOQhFyQMIw45087QQkeLawwyPd7XDW8F4rTE5xH0WDo9gn_dH-SYifE3ZoJK6Gztc1YDir- 
pdjAqdJV4dpy8UOLg-8Iw_YvCd_I-_8q3yW_IB--beDHEXD_QF6vVjRyw6qVFXcWXv3VtDr44lanT78tUikOFpBWIheVqFrryoWX1 pbm0EMe2mw2rS23tdB1K61cpHSMUle2oRtpxUsNLBPGaMCAVHnzKhnTnwGW2jgv73VhWUyLAN-Dm3zcxyQZ1g_dM9BscT62frL3CIscU1k!/dz/d5/L2dBISEvZ0FBIS9nQSEh/. Acesso em 15 maio 2020.

BRASIL. Banco Central do Brasil. Resolução n 4.679, de 31 de julho de 2018. Disponível em: https://www.bcb.gov. br/pre/normativos/busca/downloadNormativo.asp?arquivo=/Lists/Normativos/Attachments/50631/Res_4679_ v1_O.pdf. Acesso em 17 maio 2020.

BRASIL. Constituição da República Federativa do Brasil de 1988. Presidência da República, Brasília/DF. Disponível em: https://www.planalto.gov.br/ccivil_03/constituicao/constituicao.htm. Acesso em 17 maio 2020.

BRASIL. Decreto-lei no 1.940, de 25 de maio de 1982. Disponível em: http://www.planalto.gov.br/ccivil_03/ decreto-lei/Del1940.htm. Acesso em 17 maio 2020.

BRASIL. Lei complementar n 105, de 10 de janeiro de 2001. Disponível em: http://www.planalto.gov.br/ccivil_03/ leis/LCP/Lcp105.htm. Acesso em 17 maio 2020.

BRASIL. Lei n. 1.628, de 20 de junho de 1952. Disponível em: http://www.planalto.gov.br/ccivil_03/LEIS/19501969/L1628.htm. Acesso em 17 maio 2020.

BRASIL. Lei n. ${ }^{\circ}$ 4.320, de 17 de março de 1964. Disponível em: http://www.planalto.gov.br/ccivil_03/leis/l4320. htm. Acesso em 15 maio 2020.

BRASIL. Lei n. 5.662, de 21 de junho de 1971. Disponível em: http://www.planalto.gov.br/ccivil_03/LEIS/L5662. htm. Acesso em 17 maio 2020.

BRASIL. Lei n 7.998, de 11 de janeiro de 1990. Disponível em: http://www.planalto.gov.br/ccivil_03/LEIS/L7998. htm. Acesso em 17 maio 2020.

BRASIL. Lei n 8.036, de 11 de maio de 1990. Disponível em: http://www.planalto.gov.br/ccivil_03/leis/l8036consol.htm. Acesso em 17 maio 2020.

BRASIL. Lei n. ${ }^{0} 11.491$, de 20 de junho de 2007. Disponível em: http://www.planalto.gov.br/ccivil_03/_Ato20072010/2007/Lei/L11491.htm. Acesso em 17 maio 2020

BRASIL. Lei n. ${ }^{\circ}$ 12.527, de 18 de novembro de 2011. Disponível em: http://www.planalto.gov.br/ccivil_03/_ ato2011-2014/2011/lei//12527.htm. Acesso em 17 maio 2020.

BRASIL. Lei no 13.483, de 21 de setembro de 2017. Disponível em: http://www.planalto.gov.br/ccivil_03/_Ato20152018/2017/Lei/L13483.htm. Acesso em 17 maio 2020.

BRASIL. Ministério da Infraestrutura. FMM nos estados. Disponível em: http://transportes.gov.br/fundomarinhamercante.html. Acesso em 17 maio 2020.

BRASIL. Ministério do Trabalho e Emprego. Resolução n. 439, de 2 de junho de 2005. Disponível em: http://portalfat.mte.gov.br/wp-content/uploads/2016/01/Resolu\%C3\%A7\%C3\%A3o-n.-439-de-2-de-junho-de-2005.doc. Acesso em 17 maio 2020.

BRASIL. Tesouro Direito. Conheça o tesouro direto. Disponível em: http://www.tesouro.gov.br/web/stn/-/ conheca-o-tesouro-direto. Acesso em 17 maio 2020.

BRAVO, Maria Inês Souza; CORREIA, Maria Valéria Costa. Desafios do controle social na atualidade. Serviço Social \& Sociedade, São Paulo, n. 109, Jan./Mar. 2012. Disponível em: https://www.scielo.br/scielo.php?script=sci_artte xt\&pid=S0101-66282012000100008. Acesso em 19 maio 2020.

CAMPOS, Rosana; PAIVA, Denise; GOMES, Suely. Gestão da informação pública: um estudo sobre o Portal Transparência Goiás. Sociedade e Estado. vol. 28, n. 2, Brasília, May/Aug. 2013. Disponível em: https://www.scielo.br/ scielo.php?script=sci_arttext\&pid=S0102-69922013000200012. Acesso em 17 maio 2020.

CAVALCANTI, Joyce Mariella Medeiros; DAMASCENO, Larissa Mayara da Silva; SOUZA NETO, Manoel Veras de. Observância da lei de acesso à informação pelas autarquias federais do Brasil. Perspectivas em Ciência da Informação, Belo Horizonte, vol. 18, n. 4, Dec. 2013. Disponível em: https://www.scielo.br/scielo.php?script=sci_arttex t\&pid=S1413-99362013000400008. Acesso em 18 maio 2020. 
CONJUR. Transparência estatal: BNDES atende a pedido da OAB e disponibilizará dados de empréstimos. Revista Consultor Jurídico, 12 de dezembro de 2016. Disponível em: https://www.conjur.com.br/2016-dez-12/bndes-atende-oab-disponibilizara-dados-emprestimos. Acesso em 17 maio 2020.

GAMA, Janyluce Rezende; RODRIGUES, Georgete Medleg. Transparência e acesso à informação: um estudo da demanda por informações contábeis nas universidades federais brasileiras. TransInformação, Campinas, 28(1):47-57, jan./abr., 2016. Disponível em: https://www.scielo.br/pdf/tinf/v28n1/0103-3786-tinf-28-01-00047. pdf. Acesso em 17 maio 2020.

GONÇALVES, Barbara Coscrato; MACEDO, Camila da Silva; BERGAMINI, Juliana Leonardo de Oliveira. Fontes de financiamento às micro e pequenas empresas e subaproveitamento dos recursos via BNDES. Revista Executive On-Line, Bebedouro SP, 3 (1): 103-118, 2018. Disponível em: http://unifafibe.com.br/revistasonline/arquivos/ revistaexecutiveonline/sumario/78/31012019170653.pdf. Acesso em 17 maio 2020.

GONÇALVES, Tânia Carolina Nunes Machado Gonçalves; VARELLA, Marcelo D. Varella. Os desafios da Administração Pública na disponibilização de dados sensíveis. Revista Direito GV, São Paulo, vol. 14, n. 2, May/Aug. 2018. Disponível em: https://www.scielo.br/scielo.php?pid=S1808-24322018000200513\&script=sci_arttext. Acesso em 18 maio 2020.

LUHMANN, Niklas. O direito da sociedade. Tradução de Saulo Krieger. São Paulo: Martins Fontes - selo Martins, 2016.

LUHMANN, Niklas. Sociologia do direito I. Tradução de Gustavo Bayer. Rio de Janeiro: Edições Tempo Brasileiro, 1983.

MELLO, Celso Antonio Bandeira de. Liberdade de iniciativa. Intromissão estatal indevida no domínio econômico, 1999, Revista de Direito Administrativo \& Constitucional, ano 1, n. ${ }^{\circ}$ 1. Disponível em: http://www.revistaaec.com/ index.php/revistaaec/article/view/8/753. Acesso em 17 maio 2020.

PEREIRA, Thiago Rabelo Pereira; MITEFHOF, Marcelo Trindade. O Papel do BNDES e o financiamento do desenvolvimento: considerações sobre a antecipação dos empréstimos do Tesouro Nacional e a criação da TLP. Revista Economia e Sociedade. vol.27, n. 3, Campinas Sept./Dec. 2018. Disponível em: https://www.scielo.br/scielo. php?script=sci_arttext\&pid=S0104-06182018000300875. Acesso em 16 maio 2020.

SALOMÃO FILHO, Calixto. Regulação da atividade econômica: princípios e fundamentos jurídicos. 2. ed. São Paulo: Malheiros, 2008.

SILVA, Lucas Gonçalves da; SOUZA, Patrícia Verônica Nunes Carvalho Sobral de. O controle social como instrumento de defesa da democracia. Revista Jurídica Unicuritiba, Curitiba, vol. 04, n. 49, 2017, pp.207-230. Disponível em: http://revista.unicuritiba.edu.br/index.php/RevJur/article/view/2377. Acesso em 29 maio 2020.

TARANTIN JUNIOR, Wilson; VALLE, Maurício Ribeiro do. Estrutura de capital: o papel das fontes de financiamento nas quais companhias abertas brasileiras se baseiam. Revista Contabilidade \& Finanças - Revistas USP. São Paulo, v. 26, n. 69, p. 331-344, set./out./nov./dez. 2015. Disponível em: https://www.scielo.br/pdf/rcf/ v26n69/1808-057x-rcf-201512130.pdf. Acesso em 17 maio 2020.

TORRES FILHO, Ernani Teixeira; COSTA, Fernando Nogueira da. BNDES e o financiamento do desenvolvimento. Revista Economia e Sociedade. vol. 21, no. Spe, Campinas Dec. 2012. Disponível em: https://www.scielo.br/ scielo.php?script=sci_arttext\&pid=S0104-06182012000400011\&lng=pt\&tlng=pt. Acesso em 17 maio 2020.

Recebido/Received: 11.10.2019

Aprovado/Approved: 20.05 .2020 